\title{
O SIGNIFICADO DA EDUCAÇÃO PARA O TRABALHO NO MOVIMENTO DOS TRABALHADORES RURAIS SEM TERRA (MST)
}

\author{
Erika Porceli Alaniz
}

Universidade do Oeste Paulista - UNOESTE, Mestrado em Educação, Presidente Prudente, SP. Agência de fomento: CNPQ. E-mail: a.porcelirika@gmail.com

\section{RESUMO}

Este artigo discute a proposta de Educação para o trabalho na pedagogia do MST. A formação técnico-profissional nesse movimento social encontra-se profundamente integrada à forma de organização da produção nos assentamentos, à organização coletiva voltada para a luta social e a instauração da gestão democrática na escola por meio do autogoverno dos alunos, professores e comunidade. Nesse sentido, o trabalho é central na formação, pois a organização da escola e da produção é ao mesmo tempo um processo de trabalho e processo educativo.Com base na pesquisa bibliográfica, buscamos sistematizar e analisar o sentido da educação para o trabalho na formação técnico-profissional, tendo como referência, principalmente, a experiência do Instituto Educacional Josué de Castro (IEJC). Consideramos que há uma diferença essencial entre a educação profissional oficial e a proposta de educação para o trabalho defendida e implementada pelo MST.

Palavras - chave: trabalho; educação profissional; movimento social; gestão democrática.

\section{THE SIGNIFICANCE OF EDUCATION FOR WORK IN THE MOVIMENTO DOS TRABALHADORES RURAIS SEM TERRA (MST)}

\begin{abstract}
This article discusses the proposal of Education for work in the MST pedagogy. Technical and professional training in this social movement is deeply integrated into the way of organizing production in the settlements, the collective organization focused on social struggle and the establishment of democratic management in school through self-government of students, teachers and community. In this sense, work is central training, because school organization and production is simultaneously a process of work and process educativo.Com based on the literature, we sought to systematize and analyze the meaning of education for work in technical training -professional, with reference mainly to experience the Educational Institute Josué de Castro (IEJC). We believe that there is an essential difference between the official education and the proposal of education for work advocated and implemented by the MST.
\end{abstract}

Keywords: work; professional education; social movement; democratic management. 
INTRODUÇÃO

Objetivamos, com esse artigo, discutir a proposta de educação para o trabalho no Movimento dos Trabalhadores Rurais Sem Terra (MST), considerando a prática de educação e a diretriz político- pedagógica do movimento. Consideramos que há uma diferença essencial entre a educação profissional oficial e a proposta de educação para o trabalho defendida e implementado pelo MST.

Com vista a demonstrar tal hipótese, realizamos a pesquisa bibliográfica com base em teses, dissertações, livros, capítulos de livros e artigos especializados que abordem as experiências de educação para o trabalho nas escolas técnico-profissionalizantes destinada a formação de técnicos e lideranças desse movimento social. Com base nessas experiências, buscamos delinear o sentido da educação para trabalho na pedagogia do MST.

Organizamos o artigo em duas seções. Na primeira, expusemos o sentido da educação para o trabalho para o MST e indicamos que a formação profissional está profundamente atrelada à forma como se organiza a produção. Na segunda seção, expusemos a experiência do Instituto Educacional Josué de Castro (IEJC), considerado pelo MST e pela literatura especializada (CALDART, 2009; DAL RI E VIEITEZ, 2004) uma importante referência na difusão do modelo de formação profissional na perspectiva defendida por esse movimento social.

\section{O SENTIDO DA EDUCAÇÃO PARA O TRABALHO NA PEDAGOGIA DO MST}

O MST amplia o sentido da formação profissional ao buscar atrelá-la às necessidades de desenvolvimento do trabalho coletivo nos assentamentos e à luta social por reforma agrária. Caldart (2009, p.54) sistematiza algumas ideias sobre a educação para o trabalho no e do campo e aponta que ela constitui-se por outra lógica, que é oposta ao trabalho assalariado e está voltada para a produção coletiva dos trabalhadores do campo. Portanto, não se trata apenas de unir educação geral e profissional na perspectiva do mercado como se propõem as escolas públicas profissionalizantes oficiais.

Da mesma forma hoje, quando se reflete sobre a integração entre educação básica e formação específica para o trabalho, o olhar se coloca para a lógica do trabalho que predomina nas cidades. A Educação do campo, ao retomar esta reflexão sobre a relação entre educação e trabalho, se pergunta e interroga a teoria pedagógica: o que significa pensar a relação entre educação e trabalho, e fundamentalmente os processos de formação humana ou de produção do ser humano, tendo como base os processos produtivos do campo? [...] No âmbito específico sobre a formação profissional, por exemplo, pensar na lógica da agricultura camponesa não é pensar em um trabalho assalariado, que é a forma desde a qual se pensa hoje, inclusive do ponto de 
vista crítico (no debate do médio integrado desde a concepção de politecnia), a questão da formação dos trabalhadores para sua inserção nos processos produtivos. (CALDART, 2009, p.54, grifo nosso)

Essa concepção indica ser diferente da educação profissional e média oficial quando propõe vincular-se ao trabalho. Isso ocorre porque a escola constitui-se como instância separada do mundo produtivo, havendo apenas a promessa integradora quando o estudante estiver de posse da certificação. No modelo de escola oficial apartada do mundo do trabalho, os conhecimentos e conteúdos ensinados no decorrer da progressão nos níveis de ensino justificamse mais para reproduzir a hierarquia social do que propriamente as demandas de conhecimentos advindos das exigências tecnológicas e organizacionais do mundo do trabalho, principalmente se considerarmos que uma pequena parcela dos trabalhadores insere-se no trabalho complexo. Por essa razão, a educação profissional oficial, em um contexto de sofisticação tecnológica, pode oferecer, de um lado, um ensino academicista, com pouca relação estabelece com a vida e a realidade social; de outro, educação para o trabalho aligeirada a uma parcela significativa da classe trabalhadora.

Ferretti e Silva Jr (2000) salientam que têm havido certo reducionismo na compreensão da formação profissional, inclusive nos documentos oficiais. Mostram, na análise que fizeram das Diretrizes Curriculares para Educação Profissional de nível Técnico de 1999, a adesão do documento à lógica individualizante da teoria da competência. Ferretti e Silva Jr. (2000) mencionam que o documento compreende a qualificação apenas pelo ângulo dos atributos individuais do trabalhador, com base na abordagem da Psicologia, como: capacidade de raciocínio, espirito empreendedor, iniciativa própria, adaptação ao patamar tecnológico e trajetória profissional. Com isso, despreza os atributos relacionados à classe social do trabalhador, como o lugar ocupado no local de trabalho, a trajetória de luta, nível de organização de classe, os aspectos relacionados ao gênero e etnia, enquanto componentes sociais que constituem a qualificação profissional.

Em contraponto ao modelo oficial, a educação profissional defendida no programa do MST parte da atuação política dos educandos e pressupõe a simbiose entre formação técnica com a formação política. Pergher (2012), ao tratar do IEJC, que desde a sua criação em 1995 tem-se configurado como uma referência na implementação da proposta formativa do MST, salienta que a formação almejada deve voltar-se à formação humana conforme uma matriz multilateral que combina escolarização, formação de militantes e formação profissional. Desse modo, Pergher (2012, p.117) salienta que o trabalho necessário à formação humana na perspectiva almejada no 
IEJC pressupõe a superação da formação profissional na ótica do capital, a qual está pautada em conteúdos cognitivos fragmentados e na referência a um trabalho artificial, uma vez que a formação encontra-se separada da inserção concreta na prática social. No IEJC, a prática social é a principal matriz formativa e dela extraem-se as dimensões integrantes da formação, qual seja: o trabalho, a luta social, a organização coletiva, a cultura e a história (PERGHER, 2012).

Caldart et al (2013, p.215-216) esclarece que a educação para o trabalho, no âmbito do MST, não se esgota nela mesma e nem se vincula a preparação estrita ao mercado de trabalho, pois a formação para o trabalho nesse movimento social tem como preocupação:

[...] construir novas formas e relações de trabalho no campo, estreitamente vinculada a própria luta social, por isso também a consideração da "militância na organização" também como "trabalho". Em nosso horizonte está a associação de produtores livres, e, no caso do campo, através de formas cada vez mais complexas e abrangentes de atividades produtivas e de cooperação entre os trabalhadores camponeses. E está o trabalho emancipado da lógica de exploração pelo capital. Só isso. Fundamentalmente isso.

O MST, além de construir um programa educacional avançado em muitos aspectos, como por exemplo no que se refere a imbricação entre Educação, trabalho associado e gestão democrática na educação, materializa muitas das concepções e princípios presentes no seu projeto educativo por meio das escolas próprias do movimento e daqueles que ele tem influência. Dal Ri e Vieitez (2013) mencionam que o sistema escolar do MST possui três tipos de escola: a) criada pelo MST; b) estatais controladas por membros do MST; c) estatais que o MST tem influência e luta por hegemonia.

As concepções e práticas educacionais estabelecidas pelo MST são bastante arrojadas, seja quando organiza a educação por meio da gestão democrática e auto-organização dos alunos, seja quando persegue como horizonte a construção de relações de trabalho desalienadas.

Entretanto, a educação profissional no MST desenvolve-se perpassada de contradições e limites postos pela organização social capitalista. Entre eles estão, de um lado, os limites objetivos da permanência e mesmo instauração das Cooperativas de Produção Agrárias (CPAs) nos assentamentos. Mohr (2006, p.85), fundamentada em Christofolli, indica que apesar da cooperação constituir-se em uma forma superior de organização do trabalho, tais propostas têm encontrado dificuldade de se consolidarem no âmbito do MST, em grande parte das vezes, pela contradição entre o comportamento artesanal dos produtores e as exigências objetivas do trabalho associado. Quando as cooperativas se instalam ainda há a contradição advinda da sua inserção na esfera de circulação de mercadoria, integrando, portanto, a divisão social do trabalho 
capitalista. De outro lado, há um pequeno número de escolas próprias e com influência do MST, bem como o caráter ainda experimental dos projetos educativos voltados para implementação da cooperação na produção e na escola com fundamento nas teorias socialistas.

\section{A EDUCAÇÃO PROFISSIONAL ATRELADA À ORGANIZAÇÃO DO TRABALHO COLETIVO NO MST: A EXPERIÊNCIA DO INSTITUTO EDUCACIONAL JOSUÉ DE CASTRO (IEJC)}

No processo de ocupação da terra, o MST tem desencadeado inúmeras experiências educacionais que se iniciam nos acampamentos e estruturam-se nos assentamentos. Essa experiência decorre da necessidade de efetivar o direito à Educação e dar continuidade à escolarização das crianças, jovens e adultos (CALDART, 2000). Essa forma de atuação indica a compreensão de que a educação voltada para a realidade e desenvolvimento do movimento social é um aspecto fundamental.

Com intuito de ressaltarmos as concepções e práticas de educação profissional no MST, com base na literatura analisada, teremos como referência principal o curso Técnico de Administração de Cooperativas (TAC), atualmente denominado curso Técnico em Cooperativismo, do Instituto Educacional Josué de Castro (IEJC), do Instituto Técnico de Capacitação e Pesquisa da Reforma Agrária (ITERRA). Esse curso destaca-se como uma referência importante porque encontramos, nas literaturas consultadas, a efetivação da proposta pedagógica do MST em uma escola técnica própria do movimento, o que permite vislumbramos a aplicação do programa de formação do MST. Ademais, o ensino ministrado no IEJC relaciona-se diretamente com o perfil do militante que o movimento necessita, como apontaram Dal Ri e Vieitez (2004, p.46):

Para o movimento, não basta que o militante tenha formação política, ainda que esta seja essencial. Paralelamente a essa qualidade, o Movimento precisa que o seu membro tenha também capacitação técnica, bem como desenvolva as aptidões necessárias à organização coletiva da vida social, à organização coletiva da produção e de outras atividades econômicas.

A necessidade de realizar a formação técnica, de nível médio, no assentamento decorreu da forma cooperativa de produção organizada nos assentamentos. Georgen e Stédile (1991 apud Souza, 1999) salientam que o desenvolvimento da cooperação agrícola depende de condições objetivas (aspecto físico da terra, mercado e maquinário), como das condições subjetivas (grau de consciência, nível cultural, conhecimento técnico em relação à agricultura, à mecanização e aos métodos administrativos presentes na comunidade). Imbuídos dessa preocupação "a direção do MST desenvolve propostas de organização da produção, cursos de formação e experiências de coletivo de produção". (SOUZA, 1999, p.108) 
A cooperação agrícola ocorre por meio de diferentes formas de organização, sendo elas: coletiva, semicoletiva e associações (SOUZA, 1999). Entretanto, concordamos com Dal Ri e Vieitez (2004), na compreensão de que a forma de organização mais avançada é a Cooperativa de Produção Agropecuária (CPA), que se caracteriza por ser "cooperativa socializada de gestão democrática ou de autogestão". (DAL RI e VIEITEZ, 2004, p.46).

No caso do MST, a luta comum e coletiva por reforma agrária, que culmina na ocupação da terra, é o primeiro momento de organização coletiva, mas que só demonstra potencial de continuidade e enfrentamento das relações capitalistas de produção na medida em que estende para a organização do trabalho, da produção e das demais instâncias da vida social, entre elas, a escola. Podemos identificar a imbricação desses elementos no processo de organização da cooperativa de produção do MST, uma vez que essa forma de cooperação passa a requerer do movimento processo de ensino voltado para a formação profissional dos militantes.

A concepção de autogestão, nesse caso, não é apenas um modelo organizacional pois se refere a apropriação do poder pelo coletivo dos trabalhadores decorrente do processo de luta contra a ordem capitalista estabelecida na sociedade. Assim, a instauração do autogoverno envolve a tomada de decisão coletiva em todas as atividades ligadas a produção econômica, a vida social e cultural. Nesse sentido, a atuação do movimento atrela luta, organização produtiva e educação, tendo como base a crítica radical aos fundamentos da sociedade capitalista, como propriedade privada, hierarquia e divisão do trabalho.

Importante destacar que quando os trabalhadores camponeses passam a desenvolver a organização econômica no âmbito do assentamento, a faz contrapondo à lógica de organização hierárquica das instituições capitalistas e cria novas formas de organização do trabalho fundamentadas no trabalho coletivo. A instauração da cooperativa de produção elimina o atravessador e, em parte, permite que uma maior parte do valor produzido retorne aos trabalhadores sob a forma de valor de uso. Entretanto, a esfera da circulação evidencia que os camponeses são produtores de valor de troca, mercadorias, havendo captação de mais valor do decorrer do circuito da produção capitalista. (MARX, 2005)

A instauração de processo formativo com vista a desenvolver novas relações sociais de trabalho decorre desse processo de aprimoramento das formas de organização da cooperação no interior do MST e nos assentamentos (SOUZA, 1999).

Nesse atrelamento entre organização da luta social e ocupação da terra, organização da produção coletiva e educação para o trabalho nas CPAs, a autogestão tem sido um elemento estruturante nas relações de trabalho e educacionais desejadas e, em parte, implementadas. 
Assim, a autogestão constitui-se em um mecanismo fundamental nas relações sociais que se estabelecem na produção e na escola.

[...] A "auto-educação dos iguais" e "a autogestão da ordem social reprodutiva" não podem separada uma da outra. A autogestão- pelos produtores livremente associados- das funções vitais do processo metabólico social é um empreendimento progressivo- e inevitavelmente em mudança. (MÉSZÁROS, 2005, p.75)

Umas das experiências de Educação próprias do MST e que tem implementado o programa pedagógico do movimento é o IEJC. O IEJC, mantido pelo ITERRA e localizado no município de Veranópolis, surgiu com o objetivo de oferecer, em especial, formação profissional para os militantes do Movimento. Dal Ri e Vieitez (2004) esclarecem que o IEJC constitui em uma escola média e profissional com objetivo de oferecer educação geral, escolarização e formação de militantes e técnicos para atuar no MST. "Seu funcionamento está organizado em torno de cursos formais de nível médio, de educação profissional e formação de professores, criados a partir de demandas apresentadas pelos diversos setores do MST". Caldart et al $(2013$, p.23) expõe que a criação do IEJC decorreu:

[..] do objetivo de construir uma escola vinculada aos interesses de classe dos trabalhadores que vivem no e do campo e com um desenho diferente da escola capitalista, assumindo o contraponto de projeto histórico, nas circunstâncias contraditórias em que isso poderia se tornar possível. Pretendíamos ser uma escola popular, com as condições materiais mínimas de espaço e meios para trabalhar com dignidade, para desenvolver não apenas o ensino, mas também a cultura política que envolvem o processo de formação da consciência e, ao mesmo tempo, acumulou informações e produziu novos conhecimentos que servissem aos movimentos sociais e trabalhadores através da pesquisa.

Pergher (2012) salienta que a construção do IEJC retrata a necessidade do MST, em especial, construir uma proposta pedagógica diferenciada que estivesse vinculada ao projeto político e educativo do MST e subsidiasse a luta pela reforma agrária no Brasil. Para isso, conforme o Iterra (PERGHER, 2012), o IEJC deveria atender a demanda de escolarização do povo do campo, privilegiar- no método pedagógico- a formação humana, atrelar-se ao trabalho de modo a garantir, inclusive, a sustentabilidade da escola, pautar-se na organização coletiva do trabalho educativo.

No decorrer da existência do IEJC, foram criados alguns cursos destinados ao aprimoramento do trabalho nas cooperativas de produção, tais como o Laboratório Organizacional do Campo (LOC), a Formação Integrada à Produção (FIP) e o Técnico Administração 
da Cooperativa (TAC). O TAC foi a experiência melhor sucedida, como apontou Souza (1999), criado em 1993 e ainda existente no IEJC. Por essa razão, destacaremos alguns aspectos da orientação e prática pedagógica nesse curso.

Caldart (2009) menciona que os dois cursos, o magistério e o TAC, nasceram do acúmulo do MST e do IEJC no campo Educacional. Além disso, o curso TAC nasceu ligado ao desenvolvimento das discussões e práticas de cooperação dos assentamentos vinculados ao MST, com o objetivo de formar quadros capazes de organizar a produção e gestão das associações coletivas que estavam sendo construída desde a emergência do movimento. O curso orientou-se por propagar as CPAs pelos assentamentos, pois estas deveriam ser a espinha dorsal do movimento cooperativo e a proposta de cooperação nos assentamentos. (CALDART ET AL, 2013).

Uma das expectativas em torno do curso TAC, não plenamente alcançada, era de que o curso ampliasse seu foco para contemplar formas cooperativas de prestação de serviços e apoio às unidades familiares para avançar na cultura da cooperação, bem como esperava-se que os estudantes se organizassem e passassem a gerar renda por meio das empresas criadas por eles, nas quais todos participavam das decisões e repartiam os benefícios. (CALDART ET AL, 2013).

Enquanto experiência pedagógica, o exercício de gestão das empresas de forma cooperada pelos estudantes, atrelada as demais práticas formativas, foi importante instrumento de formação profissional dos educandos militantes do movimento. Contudo, do ponto de vista da sustentabilidade, Caldart et al (2013) indicaram a dificuldade de entrarem no mercado. Pergher (2012, p.128) diz que o trabalho realizado por educadores e educandos do IEJC é garantia de sobrevivência da escola, uma vez que os educandos limpam, colhem, plantam, cozinham, lavam, entre outras atividades para manter o funcionamento da escola.

\section{CONCLUSÃO}

No IEJC, a formação técnico-profissional caracteriza-se por um vínculo orgânico com o trabalho produtivo real e não alienado. Como expressão disso, os estudantes devem atuar na vida social, trazer para a escola os desafios postos pela realidade e a escola deve constituir-se em um espaço para aprimorar o processo produtivo e as relações de produção em benefício da coletividade. Além disso, a própria escola deve ser compreendida como local de trabalho e organizada sob a forma de autogestão pelos alunos.

Na escola oficial estatal, o trabalho não integra a formação profissional, pois o modelo de escola burguesa priorizou o academicismo desconectado da vida social, cujos saberes e conhecimentos em sua maior parte não tem funcionalidade útil para a comunidade a que 
pertencem. Nesse sentido, para o MST, como apontou Caldart (2009), introduzir o trabalho como princípio educativo implica também em romper com paradigma de ciência vigente da qual emana conhecimentos considerados universais e, portanto, neutros.

\section{REFERÊNCIAS}

CALDART, R.S. Educação do campo: notas para uma análise de percurso. Trabalho, Educação e Saúde, Rio de Janeiro, v.7, n.1, p.35-64, mar.-jun. 2009.

CALDART, R.S. et al. Escola em Movimento: Instituto de Educação Josué de Castro. São Paulo: Expressão Popular, 2013. 448p.

DAL RI, N. M; VIEITEZ, C.G. A educação do Movimento dos Trabalhadores Rurais Sem Terra. Revista Brasileira de Educação. maio-ago, n.26, 2004. p.44-57.

. Gestão associada e democrática nas escolas do Movimento dos Trabalhadores Rurais Sem Terra. In: RODRIGUES, F. C.; NOVAES, H.T.; BATISTA, E. L. Movimento sociais, trabalho associado e Educação para além do capital. Vol. 2. Outras Expressões: São Paulo, 2013. p.241264.

FERRETTI, C.J.; SILVA Jr, J. R. Educação profissional numa sociedade sem empregos. Cadernos de Pesquisa, n.109, mar.,2000. p.43-66. http://dx.doi.org/10.1590/S0100-15742000000100003

MARX, K. O Capital: o processo de circulação do capital. 10. ed. Rio de Janeiro: Civilização Brasileira, 2005. Livro II.

MÉSZÁROS, I. A Educação para além do capital. São Paulo: Boitempo, 2005.

PERGHER, E.G. A organização do trabalho pedagógico e a formação para o trabalho no Instituto Josué de Castro. In: AUED, B.W.; VENDRAMINI, R.C. Temas e problemas no ensino em escolas do campo. São Paulo: Outras Expressões, 2012. p.207-234.

SOUZA, M. A. As formas organizacionais de produção em assentamentos rurais do Movimento dos Trabalhadores Rurais Sem Terra - MST. 1999, 259 f. Tese. (Doutorado em Educação) Faculdade de Educação da Universidade Estadual de Campinas, Campinas. 